\title{
Return on investment of the Enhanced Recovery After Surgery (ERAS) multiguideline, multisite implementation in Alberta, Canada
}

\author{
Nguyen X. Thanh, MD, PhD \\ Alison Nelson, MN, RN \\ Xiaoming Wang, PhD \\ Peter Faris, PhD \\ Tracy Wasylak, MSc \\ Leah Gramlich,* MD \\ Gregg Nelson,* MD, PhD
}

${ }^{*}$ Contributed equally as co-senior authors.

Accepted Aug. 28, 2020

\section{Correspondence to: \\ N.X. Thanh \\ Strategic Clinical Networks \\ Alberta Health Services \\ 2-103 South Tower \\ Seventh Street Plaza \\ $10030107 \mathrm{St}$ \\ Edmonton AB T5J 3E4 \\ thanh.nguyen3@ahs.ca}

DOI: $10.1503 /$ cjs.006720
Background: Enhanced Recovery After Surgery (ERAS) is a global surgical qualityimprovement initiative. Little is known about the economic effects of implementing multiple ERAS guidelines in both the short and long term.

Methods: We performed a return on investment (ROI) analysis of the implementation of multiple ERAS guidelines (for colorectal, pancreas, cystectomy, liver and gynecologic oncology procedures) across multiple sites (9 hospitals) in Alberta using 30-, 180- and 365-day time horizons. The effects of ERAS on health services utilization (length of stay of the primary admission, number of readmissions, length of stay of the readmissions, number of emergency department visits, number of outpatient clinic visits, number of specialist visits and number of general practitioner visits) were assessed by mixed-effect multilevel multivariate negative binomial regressions. Net benefits and ROI were estimated by a decision analytic modelling analysis. All costs were reported in 2019 Canadian dollars.

Results: The net health system savings per patient ranged from $\$ 26.35$ to $\$ 3606.44$ and ROI ranged from 1.05 to 7.31, meaning that every dollar invested in ERAS brobrought $\$ 1.05$ to $\$ 7.31$ in return. Probabilities for ERAS to be cost-saving were from $86.5 \%$ to $99.9 \%$. The effects of ERAS were found to be larger in the longer time horizons, indicating that if only the 30-day time horizon had been used, the benefits of ERAS would have been underestimated.

Conclusion: These results demonstrated that ERAS multiguideline implementation was cost-saving in Alberta. To produce a better ROI, it is important to consider a broad range of health service utilizations, long-term impact, economies of scale, productive efficiency and allocative efficiency for sustainability, scale and spread of ERAS implementations.

Contexte : L'initiative de récupération améliorée après la chirurgie (RAAC) est un projet international d'amélioration de la qualité en chirurgie. On en sait peu sur les retombées économiques, tant à court qu'à long terme, de la mise en œuvre de multiples lignes directrices de RAAC.

Méthodes : Nous avons réalisé une analyse du rendement sur l'investissement (RSI) visant la mise en œuvre de multiples lignes directrices de RAAC (pour les opérations colorectales, pancréatiques, hépatiques ou d'oncologie gynécologique et la cystectomie) dans 9 hôpitaux albertains sur un horizon temporel de 30, 180 et 365 jours. L'incidence de la RAAC sur l'utilisation des services de santé (durée du séjour à l'hospitalisation initiale, nombre de réadmissions, durée du séjour à la réhospitalisation et nombre de visites à l'urgence, en consultation externe, chez un spécialiste et chez un omnipraticien) a été évaluée à l'aide d'un modèle multiniveau de régressions binomiales négatives à effets mixtes multivariés. Les bénéfices nets et le RSI ont été estimés à l'aide d'un processus de modélisation analytique décisionnelle. Tous les coûts ont été rapportés en dollars canadiens de 2019.

Résultats : Les économies nettes du système de santé allaient de 26,35 \$ à 3606,44 \$ par patient, et le RSI variait de 1,05 à 7,31 ; chaque dollar investi dans l'initiative de RAAC a donc généré un retour sur l'investissement de 1,05 \$ à 7,31 \$. Les probabilités d'économie grâce au RAAC allaient de $86,5 \%$ à $99,9 \%$. Les retombées générées augmentaient avec un horizon temporel à plus long terme, ce qui suggère que l'utilisation unique d'un horizon temporel de 30 jours aurait mené à une sousestimation des bénéfices. 


\begin{abstract}
Conclusion : Les résultats montrent que la mise en œuvre de multiples lignes directrices de RAAC a permis des économies en Alberta. En vue d'obtenir un RSI optimal, il est important de tenir compte d'une grande variété d'utilisations des services de santé, des retombées à long terme, des économies d'échelle, de l'efficacité productive et de l'efficience des allocations pour la pérennité, la mise à l'échelle et la diffusion des projets de mise en œuvre de RAAC.
\end{abstract}

E nhanced Recovery After Surgery (ERAS) is a multimodal, multidisciplinary approach to providing best practice perioperative care before, during and after surgery. ${ }^{1}$ Drawing from best practices and evidence from around the world, ERAS improves patient care related to nutrition, mobility after surgery, fluid management, anesthesia and pain control. ERAS also makes patients part of the team by involving them in preparation for their surgery and postoperative recovery (www.ahs.ca/ERAS). It is generally accepted that ERAS is effective both clinically and economically by reducing hospital length of stay, surgical complications and health services utilization (HSU) without compromising patient safety and health-related quality of life..$^{2-4}$

Alberta Health Services (AHS) established an ERAS implementation program in 2013. It piloted ERAS Society colorectal guidelines at 2 sites, and subsequently the adoption of the guidelines was expanded into 6 sites that perform more than $75 \%$ of all colorectal surgeries in Alberta. We conducted an economic evaluation in 2016 and found that the implementation of the guidelines was cost-saving. ${ }^{5}$ Specifically, the net health system savings were estimated at \$1768 (range \$920-\$2619) per patient and the return on investment ratio (ROI) was estimated at 3.8 (range 2.4- 5.1).

On the basis of this evidence, the 6 sites that adopted the ERAS guidelines for colorectal cancer have continued to use them, and the ERAS program in Alberta has spread to other surgical disciplines, including gynecologic oncology. We clinically and economically evaluated the implementation of ERAS guidelines in gynecologic oncology at the 2 hospitals that perform most of the gynecologic oncology surgery in Alberta. ${ }^{6}$ The results showed that ERAS implementation was cost effective, with a net costsaving of \$956 (range \$162-\$1636) per patient and an ROI of 2.1 (95\% confidence interval [CI] 1.2 to 2.8 ).

Although both of the previous evaluations were conducted at mutliple sites, each was based on the implementaion of a single guideline and used a short time horizon of 30 days after surgical discharge. Therefore, they may not provide a comprehensive picture of the impacts of ERAS on Alberta's health system, and they may not address the longer term impact of ERAS.

In this study, we performed an ROI analysis of the implementation of multiple ERAS guidelines (colorectal, pancreas, radical cystectomy, liver and gynecologic oncology guidelines ${ }^{7}$ ) across multiple sites (9 hospitals) (hereafter, the intervention) in Alberta. Given the complexity of ERAS, ${ }^{8}$ it is expected that the impacts of single- and multiguideline implementations will be different. Furthermore, we included time horizons of 180 days and 365 days, in addition to the 30-day time horizon, to assess the long-term effects of ERAS.

\section{Methods}

We conducted a decision tree analysis comparing return (or benefit, B) and investment (or cost, C) (Fig. 1). We calculated the net benefit $(\mathrm{NB})$ by subtracting $\mathrm{C}$ from $\mathrm{B}$, and we calculated the ROI by dividing $\mathrm{B}$ by $\mathrm{C}(\mathrm{NB}=\mathrm{B}-\mathrm{C}$, and $\mathrm{ROI}=\mathrm{B} / \mathrm{C}){ }^{9}$

In this study, we used an Alberta health system (public payer) perspective, where $C$ included investments that AHS contributed to the ERAS initiative, including costs for knowledge translation, audit data, and implementation personnel. B included savings from reductions in patients' utilization of inpatient, outpatient, and physician services by patients after the implementation of ERAS. Of the inpatient services, we included the length of stay (LOS) of the primary admission (Savings1) and the number of readmissions (Savings2). Among readmitted patients, we also calculated reductions in readmission LOS (Savings3). Of outpatient services, we included emergency department (ED) visits (Savings4) and clinic visits (Savings5). Of physician services, we included specialist visits (Savings6) and general practitioner (GP) visits (Savings7). Savings1 to Savings7 were calculated using the formulae listed in Box $1 .^{5}$

The time frame for the number of patients and investments was from Sept. 1, 2013 (when the project was started) to Sept. 30, 2018 (when the most recent Alberta Health administrative data were available). To estimate both short- and long-term effects of ERAS, we applied

Box 1. Formulae used in the analyses

- Savings $1=\mathrm{N} 1 \times(1-\operatorname{IRR} 1) \times$ primLOS $\times \mathrm{c} 1$

- Savings2 $=\mathrm{N} 1 \times(1-$ IRR2 $) \times$ readm $\times \mathrm{c} 2$

- Savings $3=$ N2 $\times(1-$ IRR3 $) \times$ readmLOS $\times$ c3

- Savings $4=\mathrm{N} 1 \times(1-$ IRR4 $) \times$ EDvisit $\times \mathrm{c} 4$

- Savings $5=\mathrm{N} 1 \times(1-$ IRR 5$) \times$ CLvisit $\times \mathrm{c} 5$

- Savings6 = N1 $\times(1-$ IRR6 $) \times$ SPvisit $\times \mathrm{c} 6$

- Savings7 $=\mathrm{N} 1 \times(1-\mid \mathrm{RR} 7) \times$ GPvisit $\times \mathrm{c} 7$

$c 1$ to $c 7=$ unit costs; CLvisit $=$ no. of outpatient clinic visits; EDvisit $=$ no. of emergency department visits; GPvisit $=$ no. of general practitioner visits; IRR1 to IRR7 = incidence rate ratios; $\mathrm{N} 1=\mathrm{no}$. of patients who underwent surgery after the implementation of ERAS; $\mathrm{N} 2=$ no. of patients who underwent surgery after the implementation of ERAS who were readmitted; primLOS = length of stay of the primary admission; readm $=$ no. of readmissions; readmLOS $=$ length of stay of readmissions; SPvisit = no. of specialist visits. 


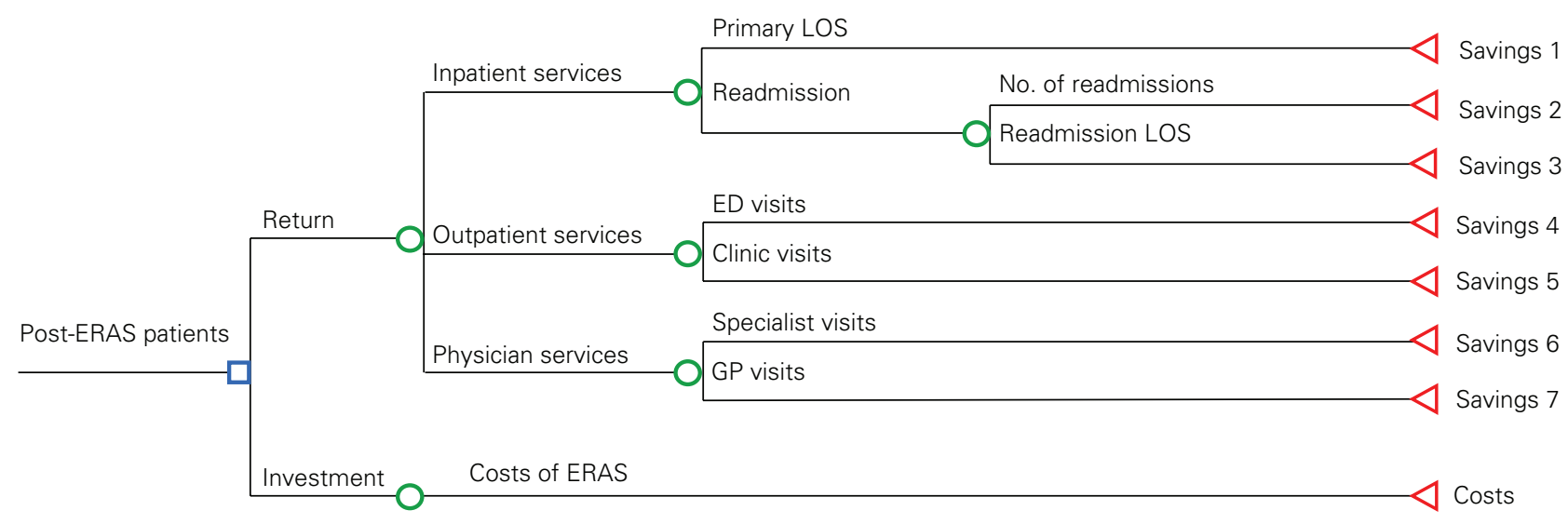

Fig. 1. Model structure. ED = emergency department; ERAS = Enhanced Recovery After Surgery; GP = general practitioner; postERAS patients = patients who underwent surgery after the implementation of ERAS guidelines; primary LOS = length of stay during the primary admission; readmission LOS = length of stay during readmissions.

3 time horizons: 30 days, 180 days and 365 days; in other words, we separately analyzed HSU and associated costs occurring within 30 days, 180 days and 365 days of surgical discharge.

\section{Statistical methods to estimate inputs for the model}

As the outcomes of interest were count variables, we used mixed-effect multilevel multivariate negative binomial regressions to estimate the effects of ERAS (incident rate ratios [IRRs]). An IRR less than 1 indicates that ERAS reduced the number of HSUs and vice versa. Covariates were patient demographic characteristics (age, sex) and clinical characteristics (the number of surgeries [patients may have more than 1 surgery], comorbidity as measured by the Charlson Comorbidity Index score, ${ }^{10}$ intensive care unit $[\mathrm{ICU}]$ admission and death), as well as characteristics of providers (e.g., site/hospital). Because the outcomes of interest in this study were HSUs and associated costs, we did not consider death as an outcome; rather, we considered it as a covariate to determine if death was associated with HSUs and associated costs. ${ }^{11}$ The multilevel analysis, including at the patient level and at the level of type of surgery, was used to account for variations or mixed effects between types of surgery.

The average LOS of the primary admission (primLOS), the number of readmissions (readm), the LOS of readmissions (readmLOS), the number of ED visits (EDvisit), the number of outpatient clinic visits (CLvisit), the number of specialist visits (SPvisit) and the number of general practitioner visits (GPvisit) were estimated among patients before the implementation of ERAS. The term (1 - IRR) multiplied by an HSU in the savings formulae in Box 1 was the difference in HSU between patients who underwent surgery before and after the implementation of ERAS (hereafter referred to as pre-ERAS and post-ERAS patients, respectively). For example, (1 - IRR) multiplied by primLOS is the difference in the LOS of the primary admission between pre-ERAS and post-ERAS patients.

Unit costs $(\mathrm{c} 1-\mathrm{c} 7)$ were also estimated among preERAS patients because if ERAS had not existed, the unit costs of post-ERAS patients would have been the same as those of pre-ERAS patients. Specifically, $\mathrm{c} 1$ was the cost per day of the primary admission LOS, c2 was the cost per readmission, $\mathrm{c} 3$ was the cost per day of the readmission LOS, c4 was the cost per ED visit, c5 was the cost per outpatient clinic visit, $c 6$ was the cost per specialist visit, and c7 was the cost per GP visit. Unit costs for inpatient and outpatient services were based on the Canadian Institute for Health Information (CIHI) Case Mix Groups+ (CMG+) methodology, which included both medical costs and nonmedical costs (e.g., costs for support and administrative departments, such as information systems, housekeeping and finance). ${ }^{12}$ The cost for each CMG+ or Comprehensive Ambulatory Classification System (CACS) group was retrieved from the Alberta Health Interactive Health Data Application. ${ }^{13}$ The cost for physician services was defined as paid amounts available in claims that physicians made to the Alberta Health Care Insurance Plan.

Of note, for $\mathrm{c} 1$ and $\mathrm{c} 3$, we did not use the average but rather the "marginal cost" per hospital day for the stays that were shortened by ERAS. The rationale for this approach was that during a hospital stay, the cost of health services in the last days of the stay is usually lower than the average and close or equal to the "hotel cost" because of the high treatment cost in the first few days when major procedures (i.e., surgery) are done. As actual data were not available, we applied the hotel cost as a percentage of the 
average cost $(43.5 \%),{ }^{5}$ which was estimated from microcosting data of colorectal surgeries before the implementation of ERAS in Montreal reported by Lee and colleagues, ${ }^{14}$ to the average cost to calculate the marginal cost.

\section{Data sources}

The ERAS Interactive Audit System (EIAS), which contains data on surgical and anesthesia outcomes, as well as data on ERAS guideline compliance for the pre-, intraand postoperative periods,${ }^{15}$ was used to identify patients who underwent procedures before and after the implementation of ERAS. AHS administrative databases, which are linkable by the patient's unique lifetime identifier, ${ }^{16}$ were used to identify HSU of the patients. Specifically, data on inpatient services were retrieved from the Discharge Abstract Database (DAD), which contains information about acute inpatient care, including treatment, examination and observation for patients occupying a hospital inpatient bed. Data elements include demographic characteristics; information on admission, discharge and transfer; provider information; diagnoses; intervention; special care unit information; and CIHI's CMG+ derived data. Data on outpatient services were retrieved from the National Ambulatory Care Reporting System, which includes information about ambulatory care that is provided in publicly funded clinic, day surgery and ED settings. Practitioner services were retrieved from the Alberta Health Care Insurance Plan claims database, which consists of claims made by physicians and allied health care practitioners (e.g., optometrists, podiatrists, podiatric surgeons and dentists). Data elements include patient information (such as identifier, demographic information, location), provider information (such as identifier, specialty, role, location, referring provider identifier and discipline) and service information (such as health service code, date of service, amount paid, diagnostic codes and shadow billed claims). The cost of intervention was retrieved from AHS Finance, Business Advisory Services (BAS) and AHS e-Manager (Oracle) financial system.

\section{Sensitivity analysis}

There were 6 scenarios in this study because for each time horizon (30, 180 and 365 d) we performed 2 scenario analyses: (1) we conservatively included the statistically significant effects $(p<0.05)$ of ERAS only and (2) we included both the statistically significant and nonsignificant effects of ERAS because the costs of the nonsignificant outcomes may still be substantial, as suggested by Stowers and colleagues. ${ }^{17}$ Within each scenario, we performed both deterministic and probabilistic sensitivity analyses for the uncertainty of all of the input parameters. In the deterministic sensitivity analysis, we used a 1-way sensitivity analysis (1 variable varied at a time) using a range from the lower to the higher value of the $95 \%$ CI of each parameter. In the probabilistic sensitivity analysis (all variables varied simultaneously), we assumed that cost variations follow a $\gamma$ distribution, HSU variations follows a Poisson distribution and IRR variations follow a normal distribution. We ran 100000 samples or trials and reported the probability for the intervention to be cost-saving.

We also performed a scenario analysis where deaths were excluded, to examine the sensitivity of this variable on the impact of ERAS on HSU and associated costs of patients undergoing surgery.

All costs and savings were inflated to 2019 Canadian dollars using the Bank of Canada Inflation Calculator, ${ }^{18}$ which uses the Canadian Consumer Price Index. Stata SE version 16.0 (StataCorp) and TreeAge Pro version 2019 R2.0 (TreeAge Software) were used for data analyses.

This study was approved by the Health Research Ethics Board at the University of Alberta, Edmonton, Canada (file no. Pro00046864). The need for written informed consent was waived.

\section{RESULts}

A total of 10415 patients underwent procedures recorded in the EIAS database in Alberta between Sept. 1, 2013, and Sept. 30, 2018. Of these, 9.7\% (1009 patients) had surgery before the implementation of ERAS and $90.3 \%$ (9406 patients) had surgery after the implementation of ERAS (Table 1).

Table 1 presents a descriptive analysis of patient characteristics. Men accounted for $46.5 \%$ of pre-ERAS and $47.5 \%$ of post-ERAS patients. The mean age was 61.3 years in the pre-ERAS group and 60.5 years in the post-ERAS group. Some patients in the sample had more than 1 surgery. On average, a pre-ERAS patient had 1.01 surgeries and a post-ERAS patient had 1.10 surgeries during the study period. Mean Charlson comorbidity index scores were 1.98 among pre-ERAS patients and 1.73 among post-ERAS patients. A total of 54 pre-ERAS patients $(5.4 \%)$ and 284 post-ERAS patients $(3.0 \%)$ were admitted to the ICU. In terms of in-hospital all-cause mortality, the percentages among pre-ERAS patients were $1.3 \%, 2.8 \%$ and $5.1 \%$ in 30 days, 180 days and 365 days after surgical discharge, respectively. The corresponding percentages for post-ERAS patients were $1.1 \%, 2.1 \%$ and $2.9 \%$. Of note, this study focused on HSU and associated costs; the difference in mortality between pre- and postERAS patients will be investigated in future studies.

In the entire sample, colorectal procedures were the most common type of surgery $(73.7 \%)$, followed by procedures relating to gynecologic oncology $(15.3 \%)$, the pancreas $(5.4 \%)$, the liver $(3.0 \%)$ and radical cystectomy $(2.7 \%)$. The differences in the frequencies of the various types of surgery are due to differences in both the timing 


\begin{tabular}{|c|c|c|c|c|}
\hline \multirow[b]{2}{*}{ Characteristic } & \multicolumn{3}{|c|}{ No. $(\%)$ of patients* } & \multirow[b]{2}{*}{$p$ value } \\
\hline & $\begin{array}{l}\text { Pre-ERAS } \\
n=1009\end{array}$ & $\begin{array}{l}\text { Post-ERAS } \\
n=9406\end{array}$ & $\begin{array}{c}\text { Total } \\
n=10415\end{array}$ & \\
\hline Sex & & & & 0.52 \\
\hline Male & 469 (46.5) & 4472 (47.5) & 4941 (47.4) & \\
\hline Female & $540(53.5)$ & $4934(52.5)$ & $5474(52.6)$ & \\
\hline Age, $y r$, mean $\pm S D$ & $61.3 \pm 13.6$ & $60.5 \pm 14.1$ & $60.5 \pm 14.1$ & $<0.05$ \\
\hline No. of surgeries, mean $\pm S D$ & $1.01 \pm 1.12$ & $1.10 \pm 0.32$ & $1.09 \pm 0.31$ & $<0.001$ \\
\hline $\begin{array}{l}\text { Charlson Comorbidity Index } \\
\text { score, mean } \pm \text { SD }\end{array}$ & $1.98 \pm 1.26$ & $1.73 \pm 1.25$ & $1.75 \pm 1.25$ & $<0.001$ \\
\hline Admitted to ICU & $54(5.4)$ & $284(3.0)$ & $338(3.2)$ & $<0.001$ \\
\hline \multicolumn{5}{|l|}{ All-cause death in hospital } \\
\hline Within $30 \mathrm{~d}$ & $13(1.3)$ & $103(1.1)$ & $116(1.1)$ & 0.49 \\
\hline Within $180 \mathrm{~d}$ & $28(2.8)$ & $194(2.1)$ & $222(2.1)$ & 0.10 \\
\hline Within $365 d$ & $51(5.1)$ & $271(2.9)$ & $322(3.1)$ & $<0.001$ \\
\hline \multicolumn{5}{|l|}{ Site } \\
\hline Hospital 1 & $286(28.3)$ & $2242(23.8)$ & $2528(24.3)$ & \\
\hline Hospital 2 & $103(10.2)$ & $303(3.2)$ & 406 (3.9) & \\
\hline Hospital 3 & $49(4.9)$ & $660(7.0)$ & 709 (6.8) & \\
\hline Hospital 4 & $49(4.9)$ & $989(10.5)$ & $1038(10)$ & \\
\hline Hospital 5 & $115(11.4)$ & $1525(16.2)$ & $1640(15.7)$ & \\
\hline Hospital 6 & $230(22.8)$ & $1277(13.6)$ & $1507(14.5)$ & \\
\hline Hospital 7 & $50(5.0)$ & $205(2.2)$ & $255(2.4)$ & \\
\hline Hospital 8 & $50(5.0)$ & $373(4.0)$ & $423(4.1)$ & \\
\hline Hospital 9 & $77(7.6)$ & $1832(19.5)$ & 1909 (18.3) & \\
\hline \multicolumn{5}{|l|}{ Type of surgery } \\
\hline Colorectal & 497 (49.3) & $7176(76.3)$ & $7673(73.7)$ & \\
\hline Gynecologic oncology & $152(15.1)$ & $1438(15.3)$ & $1590(15.3)$ & \\
\hline Pancreas & $159(15.8)$ & 408 (4.3) & $567(5.4)$ & \\
\hline Liver & 100 (9.9) & $208(2.2)$ & $308(3.0)$ & \\
\hline Cystectomy & $101(10.0)$ & $176(1.9)$ & $277(2.7)$ & \\
\hline
\end{tabular}

of the implementation of ERAS for different procedures and the volume of surgeries.

Table 2 presents the HSU of pre-ERAS patients, the impact of ERAS (IRR), the number of post-ERAS patients, unit costs and savings by outcome of interest. For the time horizon of 30 days, statistically significant IRRs were found in the LOS of the primary admission $(0.91, p<0.001)$. Multiplying ( 1 - IRR) with the pre-ERAS HSU, with the number of post-ERAS patients and with the unit cost, we estimated the savings associated with the reduction in LOS for the primary admission to be $\$ 12.60$ million for the 30 -day time horizon. From this, in scenario 1, we subtracted and divided by the total cost of ERAS (\$5.38 million) to calculate $\mathrm{NB}$ at $\$ 7.22$ million and ROI at 2.34, respectively, meaning that every dollar invested in ERAS would bring \$2.34 in return. In scenario 2 where nonsignificant effects were also included, the total savings were $\$ 13.64$ million, and $\mathrm{NB}$ was estimated $\$ 8.26$ million and ROI at 2.53. The observed negative savings for readmissions, specialist visits and GP visits were due to the increases in these outcomes (IRR > 1).
The effects of ERAS on reducing the number of readmissions and the number of ED visits were statistically significant in the time horizon of 180 days. IRR for the number of readmissions was $0.88(p<0.05)$ and IRR for the number of ED visits was $0.84(p<0.01$, Table 2$)$. However, these effects were not statistically significant in the time horizon of 365 days. Of note, the observed increases in the number of readmissions, the number of specialist visits and the number of GP visits within 30 days of surgical discharge were temporary as they all decreased in the longer follow-ups (all IRRs for these outcomes were less than 1 in the time horizons 180 days and 365 days).

For the bottom lines, in the 180-day time horizon, total $\mathrm{NB}$ was estimated from $\$ 17.10$ million to $\$ 26.65$ million and ROI from 4.18 to 5.95 for scenarios 1 and 2, respectively. The corresponding numbers for the 365-day time horizon were from $\$ 7.03$ to $\$ 19.19$ million and from 2.31 to 4.57 (Table 2).

Dividing the total NB by the number of patients, we estimated the NB per patient at $\$ 768.12$ and $\$ 877.71$ for scenarios 1 and 2, respectively, in the time horizon of 


\begin{tabular}{|c|c|c|c|c|c|c|}
\hline \multirow[b]{2}{*}{ Outcome } & \multirow[b]{2}{*}{ Pre-ERAS } & \multirow[b]{2}{*}{ IRR } & \multirow{2}{*}{$\begin{array}{c}\text { No. of } \\
\text { post-ERAS } \\
\text { patients }\end{array}$} & \multirow[b]{2}{*}{ Unit cost } & \multicolumn{2}{|c|}{ Savings (millions)* } \\
\hline & & & & & Scenario 1 & Scenario 2 \\
\hline \multicolumn{7}{|l|}{ Time horizon 30 days } \\
\hline LOS of primary admission, $d$ & 8.98 & $0.91 \S$ & 9406 & $\$ 1665.62$ & $\$ 12.60$ & $\$ 12.60$ \\
\hline No. of readmissions & 0.19 & 1.13 & 9406 & $\$ 17032.12$ & & (\$3.89) \\
\hline LOS of readmissions, d & 11.16 & 0.80 & 2017 & $\$ 1113.90$ & & $\$ 4.92$ \\
\hline No. of ED visits & 0.58 & 0.87 & 9406 & $\$ 602.85$ & & $\$ 0.41$ \\
\hline No. of clinic visits & 1.21 & 0.95 & 9406 & $\$ 328.61$ & & $\$ 0.19$ \\
\hline No. of specialist visits & 17.92 & 1.01 & 9406 & $\$ 418.16$ & & $(\$ 0.51)$ \\
\hline No. of GP visits & 2.91 & 1.02 & 9406 & $\$ 170.32$ & & $(\$ 0.10)$ \\
\hline Total benefit (millions) & & & & & $\$ 12.60$ & $\$ 13.64$ \\
\hline Total cost (millions) & & & & & $\$ 5.38$ & \\
\hline Net benefit (millions) & & & & & $\$ 7.22$ & $\$ 8.26$ \\
\hline Net benefit per patient & & & & & $\$ 768.12$ & $\$ 877.71$ \\
\hline Return on investment ratio & & & & & 2.34 & 2.53 \\
\hline \multicolumn{7}{|l|}{ Time horizon 180 days } \\
\hline LOS of primary admission, $d$ & 8.98 & $0.91 \S$ & 9406 & $\$ 1665.62$ & $\$ 12.63$ & $\$ 12.63$ \\
\hline No. of readmissions & 0.50 & $0.88 \dagger$ & 9406 & $\$ 15494.09$ & $\$ 8.65$ & $\$ 8.65$ \\
\hline LOS of readmissions, $d$ & 8.76 & 0.88 & 3082 & $\$ 1372.35$ & & $\$ 4.37$ \\
\hline No. of ED visits & 1.34 & $0.84 \ddagger$ & 9406 & $\$ 605.26$ & $\$ 1.21$ & $\$ 1.21$ \\
\hline No. of clinic visits & 4.32 & 0.94 & 9406 & $\$ 363.55$ & & $\$ 0.95$ \\
\hline No. of specialist visits & 27.28 & 0.95 & 9406 & $\$ 302.31$ & & $\$ 4.03$ \\
\hline No. of GP visits & 8.76 & 0.98 & 9406 & $\$ 113.37$ & & $\$ 0.20$ \\
\hline Total benefit (millions) & & & & & $\$ 22.48$ & $\$ 32.03$ \\
\hline Total cost (millions) & & & & & $\$ 5.38$ & \\
\hline Net benefit (millions) & & & & & $\$ 17.10$ & $\$ 26.65$ \\
\hline Net benefit per patient & & & & & $\$ 1817.77$ & $\$ 2833.18$ \\
\hline Return on investment ratio & & & & & 4.18 & 5.95 \\
\hline \multicolumn{7}{|l|}{ Time horizon 365 days } \\
\hline LOS of primary admission, $d$ & 8.98 & $0.91 \S$ & 9406 & $\$ 1665.62$ & $\$ 12.41$ & $\$ 12.41$ \\
\hline No. of readmissions & 0.72 & 0.94 & 9406 & $\$ 15385.37$ & & $\$ 6.21$ \\
\hline LOS of readmissions, $d$ & 8.36 & 0.98 & 3860 & $\$ 1484.13$ & & $\$ 0.99$ \\
\hline No. of ED visits & 1.91 & 0.90 & 9406 & $\$ 608.14$ & & $\$ 1.14$ \\
\hline No. of clinic visits & 7.21 & 0.95 & 9406 & $\$ 385.94$ & & $\$ 1.20$ \\
\hline No. of specialist visits & 35.62 & 0.97 & 9406 & $\$ 254.84$ & & $\$ 2.35$ \\
\hline No. of GP visits & 14.90 & 0.98 & 9406 & $\$ 97.07$ & & $\$ 0.27$ \\
\hline Total benefit (millions) & & & & & $\$ 12.41$ & $\$ 24.57$ \\
\hline Total cost (millions) & & & & & $\$ 5.38$ & \\
\hline Net benefit (millions) & & & & & $\$ 7.03$ & $\$ 19.19$ \\
\hline Net benefit per patient & & & & & $\$ 47.01$ & $\$ 2040.06$ \\
\hline Return on investment ratio & & & & & 2.31 & 4.57 \\
\hline \multicolumn{7}{|c|}{$\begin{array}{l}\text { ED = emergency department; ERAS = Enhanced Recovery After Surgery; GP = general practitioner; IRR = incident rate ratio; LOS = length of stay. } \\
\text { *Except for net benefit per patient. Values in parentheses are losses. } \\
\dagger p<0.05 \text {. } \\
\ddagger p<0.01 . \\
\S p<0.001\end{array}$} \\
\hline
\end{tabular}

30 days. The corresponding numbers were $\$ 1817.77$ and $\$ 2833.18$ in the time horizon of 180 days and $\$ 747.01$ and $\$ 2040.06$ in the time horizon of 365 days.

\section{Sensitivity analysis results}

Deterministic sensitivity analyses showed that, for all scenarios, total $\mathrm{NB}$ was from $\$ 0.25$ million $(\$ 26.35$ per patient) to $\$ 33.92$ million ( $\$ 3606.44$ per patient), and ROI was from 1.05 to 7.31 (Table 3). The most sensitive variables were the impact of ERAS on the LOS of the primary admission, followed by the impact on the number of readmissions, and the impact on the number of ED visits.

Probabilistic sensitivity analyses showed that the probabilities for ERAS to be cost-saving were from $86.5 \%$ to $99.9 \%$. The best effects of ERAS were found within 180 days of surgical discharge, followed by the effects within 365 days. This finding suggests that if only the 


\begin{tabular}{|c|c|c|c|c|c|c|}
\hline \multirow[b]{2}{*}{ Outcome } & \multicolumn{3}{|c|}{ Scenario 1} & \multicolumn{3}{|c|}{ Scenario 2} \\
\hline & Average & Low & High & Average & Low & High \\
\hline \multicolumn{7}{|l|}{ Time horizon 30 days } \\
\hline Total net benefit (millions) & $\$ 7.22$ & $\$ 0.25$ & $\$ 12.91$ & $\$ 8.26$ & $\$ 1.28$ & $\$ 13.94$ \\
\hline Net benefit per patient & $\$ 768.12$ & $\$ 26.35$ & $\$ 1372.54$ & $\$ 877.71$ & $\$ 135.93$ & $\$ 1482.12$ \\
\hline Return on investment ratio & 2.34 & 1.05 & 3.40 & 2.53 & 1.24 & 3.59 \\
\hline Probability & \multicolumn{3}{|c|}{$93.3 \%$} & \multicolumn{3}{|c|}{$86.5 \%$} \\
\hline \multicolumn{7}{|l|}{ Time horizon 180 days } \\
\hline Total net benefit (millions) & $\$ 17.10$ & $\$ 8.46$ & $\$ 24.37$ & $\$ 26.65$ & $\$ 18.00$ & $\$ 33.92$ \\
\hline Net benefit per patient & $\$ 1817.77$ & $\$ 898.95$ & $\$ 2591.36$ & $\$ 2833.18$ & $\$ 1914.03$ & $\$ 3606.44$ \\
\hline Return on investment ratio & 4.18 & 2.57 & 5.53 & 5.95 & 4.35 & 7.31 \\
\hline Probability & \multicolumn{3}{|c|}{$97.5 \%$} & \multicolumn{3}{|c|}{$99.9 \%$} \\
\hline \multicolumn{7}{|l|}{ Time horizon 365 days } \\
\hline Total net benefit (millions) & $\$ 7.03$ & $\$ 0.25$ & $\$ 12.91$ & $\$ 19.19$ & $\$ 6.71$ & $\$ 29.71$ \\
\hline Net benefit per patient & $\$ 747.01$ & $\$ 26.32$ & $\$ 1372.46$ & $\$ 2040.06$ & $\$ 713.41$ & $\$ 3158.86$ \\
\hline Return on investment ratio & 2.31 & 1.05 & 3.40 & 4.57 & 2.25 & 6.52 \\
\hline Probability & \multicolumn{3}{|c|}{$93.0 \%$} & \multicolumn{3}{|c|}{$97.2 \%$} \\
\hline
\end{tabular}

30-day time horizon had been used, the benefits of ERAS would have been underestimated.

If deaths were excluded, the results were similar. This is most likely because of the small number and proportion of deaths in the cohorts.

\section{Discussion}

This study used a modelling technique together with realworld data to estimate net benefits and ROIs of the multiguideline, multisite implementation of ERAS between 2013 and 2018 in Alberta. The results showed that the implementation was cost-saving. For all scenarios, the net health system savings per patient ranged from $\$ 26.35$ to $\$ 3606.44$ and the ROI ranged from 1.05 to 7.31 , meaning that every dollar invested in ERAS would bring \$1.05 to $\$ 7.31$ in return. The probabilities for ERAS to be costsaving were from $86.5 \%$ to $99.9 \%$. The impacts of ERAS were found to be larger in the longer time horizons used in this study, indicating that if only the 30-day time horizon had been used, the benefits of ERAS would have been underestimated.

To our knowledge, this is the first study evaluating the economic impact of ERAS multiguideline implementation in Canada. The results are in line with those of previous single-guideline studies in the sense that ERAS is costsaving. ${ }^{2-6}$ Of note, ROIs vary among studies and types of surgery. There are several possible explanations for this, which can be grouped into 3 categories: methodology, productive efficiency and allocative efficiency.

The first category refers to differences in the methods used in each study in terms of HSU and cost components and time horizons. For example, the gynecologic oncology ERAS study ${ }^{6}$ included only the LOS for the primary admission, whereas the colorectal ERAS study ${ }^{5}$ and the present study also included other HSUs, such as readmission, outpatient services and physician services. The previous studies followed ERAS patients for 30 days after discharge ${ }^{5,6}$ whereas the current study also followed the patients for 180 days and for 365 days (in addition to 30 days) to investigate the long-term impacts of ERAS. From this category, we find that ROI is higher when more cost components (health services) and longer time horizons are used.

The second category (productive efficiency) refers to the difference in costs of ERAS implementation. For example, the cost per patient in the study of ERAS gynecologic oncology surgery guideline implementation was $\$ 906,{ }^{6}$ whereas it was $\$ 638$ in the colorectal surgery study ${ }^{5}$ and $\$ 572$ in the current study. From this category, we find that ROI is higher when the cost of ERAS implementation is lower. We also find that an economy of scale is applicable here given the numbers of patients in those 3 studies were 367,1295 and 9406, respectively. This is related to the fact that there is a core infrastructure for implementing ERAS and with multiple guidelines, the fixed costs get spread over a larger volume of procedures, creating a health system gain for the investment.

Finally, the third (allocative efficiency) category refers to differences in types of surgery. Studies show that ERAS affects different types of surgery differently. For example, the IRR of LOS for the primary admission was 0.72 in gynecologic oncology surgery, ${ }^{6} 0.83$ in colorectal surgery ${ }^{5}$ and 0.91 in the current study. Furthermore, different types of surgery may have different complexity levels and thereby different LOS for the primary admission and associated costs. As a result, the savings associated with different types of surgery would differ from each other even if the impacts of ERAS were the same among different types of surgery. From this category, we find that ROI is higher 
when the surgery has a longer LOS for the primary admission and a higher cost per day. For example, the average LOS for the primary admission of pre-ERAS patients was 9.04 days and the cost per day was $\$ 3600$ for colorectal surgery, ${ }^{5}$ whereas for gynecologic oncology surgery these numbers were 6.4 days and $\$ 2397$, respectively. ${ }^{6}$ Therefore, despite the stronger impact of ERAS (smaller IRR), the savings were less for gynecologic oncology surgery $(6.4 \times[1-0.72] \times[2397 \times 43.5 \%]=\$ 1869)$ than for colorectal surgery $(9.04 \times[1-0.83] \times[3600 \times 43.5 \%]=$ $\$ 2407)$. Of note, $43.5 \%$ is the percentage of hotel cost used to calculate the cost per day shortened by ERAS. ${ }^{5,6}$

\section{Limitations}

Although this study has many strengths, including the reference of the Consolidated Health Economic Evaluation Reporting Standards (CHEERS) statement for health economic evaluation methodology, ${ }^{19}$ the inclusion of physician services to study how cost is transferred from the hospital to the community setting if there are unintended effects of shortened LOS for the primary admission, and the inclusion of 180- and 365-day time horizons to study the long-term effects of ERAS, there are some limitations to be acknowledged. First, the estimated savings in this study are not in cash but rather a cost avoidance. This would have been larger if benefits associated with "free capacity" had been included. That is, as ERAS shortens hospital LOS, there will be more space (e.g., hospital beds) and staff to serve other patients, saving health system resources, reducing wait times and thereby improving patients' outcomes and satisfaction. A second limitation relates to the difference in cohorts. The preERAS patients were from a historical cohort for whom unit costs were estimated. The post-ERAS patients comprised a prospectively collected cohort. Given that health care costs increase over time, ${ }^{20}$ it is possible that the savings reported may have been underestimated. However, the sensitivity analyses allowing every unit cost to vary from the lower to upper values of the $95 \%$ CI would minimize this. Third, given that we took a health system rather than a societal perspective, as indirect cost (e.g., lost productivity) was not included, our study probably underestimated the total benefits of ERAS for society. This is because by shortening hospital LOS, ERAS would enable patients and their caregivers to return to work sooner. The total benefits of ERAS for society would be further underestimated as costs and savings for community health services (e.g., physiotherapy, acupuncture) and out-of-pocket payments for patients were not included. ${ }^{14}$ Fourth, as data were not available, this study did not include health-related quality of life for patients nor health care professional satisfaction. Future studies taking a societal perspective to include these outcomes as well as the costs and benefits relating to productivity losses, community health services and out-of-pocket payments would be desirable. Finally, one may argue that there is possibly a selection bias as there were statistically significant differences in some characteristics between pre- and post-ERAS patients. However, we believe that multivariate and sensitivity analyses minimized this bias. Also, the multilevel regression analysis controlled for mixed effects among different types of surgery.

\section{Conclusion}

Our results have demonstrated that ERAS multiguideline implementation is cost-saving in Alberta. Our findings also show that to produce a better ROI, it is important to consider a broad range of HSUs, long-term impact, economies of scale, productive efficiency and allocative efficiency for sustainability, scale and spread of ERAS implementations.

Acknowledgements: The authors acknowledge the work and contribution of the provincial implementation teams, including organizational partners, ERAS provincial implementation leadership, implementation site partners and unit teams, ERAS surgeon leadership, ERAS anesthesiology leadership, provincial site coordinators, and data collection and analytic teams.

Affiliations: From the Strategic Clinical Networks, Alberta Health Services, Edmonton and Calgary, Alta. (Thanh, Wasylak); the Surgery Strategic Clinical Network, Alberta Health Services, Calgary, Alta. (A. Nelson); Analytics, Data Integration, Measurement and Reporting, Alberta Health Services, Edmonton and Calgary, Alta. (Wang, Faris); the Department of Medicine, Faculty of Medicine and Dentistry, University of Alberta, Edmonton, Alta. (Gramlich); and the Section of Gynecologic Oncology, Tom Baker Cancer Centre, University of Calgary, Calgary, Alta. (G. Nelson).

Funding: This study was funded by Alberta Health Services and a Partnership for Research and Innovation in the Health System (PRIHS) research grant from Alberta Innovates. The funders played no role in the research.

Competing interests: G. Nelson is secretary of the ERAS Society. No other competing interests were declared.

Contributors: N. Thanh, A. Nelson, L. Gramlich and G. Nelson designed the study. N. Thanh, A. Nelson and X. Wang acquired the data, which N. Thanh, A. Nelson, P. Faris, T. Wasylak, L. Gramlich and G. Nelson analyzed. N. Thanh, A. Nelson, P. Faris, L. Gramlich and G. Nelson wrote the manuscript, which N. Thanh, A. Nelson, X. Wang, P. Faris, T. Wasylak and G. Nelson revised. All authors approved the final version to be published.

\section{References}

1. Ljunqqvist $\mathrm{O}$, Scott M, Fearon KC. Enhanced recovery after surgery: a review. FAMA Surg 2017;152:292-8.

2. Varadhan KK, Neal KR, Dejong CHC, et al. The enhanced recovery after surgery (ERAS) pathway for patients undergoing major elective open colorectal surgery: a meta-analysis of randomized controlled trials. Clin Nutr 2010;29:434-40.

3. Greco M, Capretti G, Beretta L, et al. Enhanced recovery program in colorectal surgery: a meta-analysis of randomized controlled trials. World f Surg 2014;38:1531-41.

4. Ljungqvist O, Thanh NX, Nelson G. ERAS-value based surgery. $\mathcal{F}$ Surg Oncol 2017;116:608-12.

5. Thanh NX, Chuck AW, Wasylak T, et al. An economic evaluation of the Enhanced Recovery After Surgery (ERAS) multisite implementation program for colorectal surgery in Alberta. Can 7 Surg 2016;59:415-21. 
6. Bisch SP, Wells T, Gramlich L, et al. Enhanced Recovery After Surgery (ERAS) in gynecologic oncology: aystem-wide implementation and audit leads to improved value and patient outcomes. Gynecol Oncol 2018;151:117-23.

7. Alberta Health Services. Enhanced Recovery After Surgery (ERAS). Available: www.albertahealthservices.ca/scns/Page 10959.aspx (accessed 5 Feb. 2020).

8. Gramlich LM, Sheppard CE, Wasylak T, et al. Implementation of Enhanced Recovery After Surgery: a strategy to transform surgical care across a health system. Implement Sci 2017;12:67.

9. Drummond MF, Sculpher MJ, Torrance GW, et al. Methods for the economic evaluation of health care programmes. 3rd ed. Oxford (UK): Oxford University Press; 2005.

10. Quan H, Li B, Couris CM, et al. Updating and validating the Charlson comorbidity index and score for risk adjustment in hospital discharge abstracts using data from 6 countries. Am 7 Epidemiol 2011;173:676-82.

11. Thanh NX, Toye J, Savu A, et al. Health service use and costs associated with low birth weight - a population level analysis. 7 Pediatr 2015;167:551-6.e1.

12. CIHI. CMG+. Available: www.cihi.ca/en/cmg (accessed 21 Jan. 2020).

13. Alberta Health, Analytics and Performance Reporting Branch. Interactive health data application: dementia. Available: www.ahw.gov.
ab.ca/IHDA_Retrieval/ShowMetaDataNotesServlet?2849 (accessed 21 Jan. 2020).

14. Lee L, Mata J, Ghitulescu GA, et al. Cost-effectiveness of enhanced recovery versus conventional perioperative management for colorectal surgery. Ann Surg 2015;262:1026-33.

15. ERAS Society. ERAS / interactive audit. Available: https://erassociety. org/interactive-audit/ (accessed 5 Feb 2020)

16. Alberta Health, Analytics and Performance Reporting Branch. Overview of administrative health datasets. Available: open.alberta.ca/ dataset/657ed26d-eb2c-4432-b9cb-0ca2158f165d/resource/38f47433 -b33d-4d1e-b959-df312e9d9855/download/research-health-datasets. pdf (accessed 21 Jan. 2020).

17. Stowers MDJ, Lemanu DP, Hill AG. Health economics in Enhanced Recovery After Surgery programs. Can 7 Anaesth 2015; 62:219-30.

18. Bank of Canada. Inflation calculator. Available: www.bankofcanada. $\mathrm{ca} / \mathrm{rates} / \mathrm{related} /$ inflation-calculator/ (accessed 6 Feb. 2020).

19. Husereau D, Drummond M, Petrou S, et al. Consolidated Health Economic Evaluation Reporting Standards (CHEERS) statement. Pharmacoeconomics 2013;31:361-7.

20. Statista. Total health expenditure per capita in Canada from 1975 to 2019. Available: www.statista.com/statistics/436378/total-health -spending-per-capita-canada/ (accessed 21 Jul. 2020). 